\title{
Survival strategies for overseas doctors
}

\author{
Swaran P. Singh
}

\begin{abstract}
So, you have recently arrived in Britain. You are in a state of bewildered excitement, getting used to a strange new world. All four seasons occur in the same day. Strangers smile at you warmly while people avoid your gaze in the London underground. Everyone despises the party that seems perpetually in power. You believed that this country was class-ridden, yet you call your boss by first name. Trains run on time, but everyone complains about them. You are 'gobsmacked', and still uncertain of its meaning. Here are a few tips to help you find your personal niche as a psychiatrist in this strange and fascinating country.
\end{abstract}

\section{Names}

Announce your name clearly when you meet people. The diversity of accents in Britain is most entertaining in its treatment of foreign names. The successive distortions of one's name can be an endless source of amusement or pain. After the Preet in my name was changed to 'Preep' and later 'Creep', I decided to drop it completely when introducing myself. Venkat, a friend working in London, still winces every time he is called 'Vacant' by the switchboard.

\section{Food}

You are likely to eat in the hospital mess for some months before the assault of the insipid on your taste buds forces you to start cooking. There is no need to believe that hospital cooks are experts in black magic, able to boll away every remnant of flavour from a wide variety of food items. It won't be long before you can appreciate the inherent qualities of a boiled potato. Consider yourself truly integrated into British society when you start looking upon Indian food as a fitting challenge to your machismo, to be boldly confronted after a few pints. The British have been led to believe that Indian food is made by throwing lumps of meat into an oily mixture of chillies and gunpowder. A quick way of making friends is to invite people over for some authentic Indian cooking and dispel the notion that Indians consider dripping sweat over food, bleary-eyed and runny-nosed, an uplifting experience in spiritual or culinary terms. Remember too, that the British have dinner at noon and 'eat' their tea.

\section{Meetings}

George Mikes wrote that forming queues is a strange passion that the British indulge in, a single person often making an orderly queue of one at bus-stops. In psychiatric practice, holding meetings has a similar fascination. You may find yourself spending more time talking about patients than to them. The result of these meetings will often impress upon you the truth behind the saying that a camel is a horse put together by a committee. So it is important to understand the rules of conduct.

\section{(a) Never disagree with anyone}

Everyone has a right to be right. This conceals the greatest advantage of multidisciplinary team work: no one can ever be blamed (contrary to the conventional wisdom that to err is human, to blame it on someone else is even more human). People will say 'interesting' when they agree with you and 'very interesting' when they think you ought to be locked up for your vlews. Maintain this noble tradition by vigorously agreeing with social workers when they denounce ECT as diabolical, devious, dangerous and politically incorrect.

\section{(b) Don't show off your theoretical knowledge}

You may have been taught the importance of phenomenology in your training back home. You may also naively believe that knowing the difference between euphoria, elation and exaltation is important in describing manic symptomatology. Perish all such grandiose ideas. "This rather pleasant young lad has been up and down recently and is now rather on the high side" is more humanely descriptive, especially if you describe the same individual as a "pathetic wimp" in the discharge letter to the GP. 


\section{(c) Learn the key issues}

Every patient in Britain has a key-worker. These are easily identified as the individuals who are away on holiday when the patient is being discussed. Sometimes they may have just returned from a holiday or sick-leave to convince you that they are not abstract concepts but are living entities. Their existence justifies everyone else's ignorance of the case. You may discover at the end of two hours of considered, and rather serious sounding discussion, that you are still unaware of the age and gender of the patient. Queries in this regard will usually be answered by other team members with a pleasant "I don't know, I am not the key-worker". You may sometimes meet the elusive key-worker, usually in the corridor. Remember then that key-workers are profoundly philosophical and carry grave responsibilities. So questions about the age or gender of the patient may evoke the response "I am still struggling with that one". Many a keyworker has brought me close to tears with images of such poignant struggles.

\section{(d) Use appropriate jargon}

Don't talk to your patient - have a 'one-to-one in a therapeutic setting'. Always insist: 'there are family dynamics', disregarding the fact that this is as meaningless as saying that 'the patient has a blood pressure'. 'Struggle' with answers - don't simply know facts (see above). When a drunk throws a chair at you with the idea of cracking your skull, consider this the challenging be- haviour of a vulnerable individual'. Patient's attempts to fool you are 'maladaptive coping strategies'. 'Community care' 'purchased' by 'consumers' that allows 'autonomy' and 'empowers' the 'clients' is desirable, everything else results in 'institutionalisation'.

When in doubt, blame 'financial constraints'.

\section{(e) Appear busy}

When in corridors, rush frantically, even from the coffee room to the sandwich bar. If you meet colleagues on the way, project the heavilyweighed-down-by-the-woes-of-the-world look and suggest that they may be able to talk to you in a few weeks time provided new referrals don't turn up. For instance, a query about what time it is may reasonably be answered in about ten weeks.

It is remarkably easy to feel comfortable and relaxed in this country. You must not allow nostalgia to colour your judgement. Follow the instructions provided, and you may soon, in the words of Ogden Nash, find yourself "thrilled and tinglish" at belonging to an exclusive club:

"A club to which benighted bounders of Frenchmen and Germans and Italians et cetera cannot even aspire to belong.

Because they don't even speak English, and Americans are worst of all because they speak it wrong".

Swaran P. Singh, Senior Registrar in General Adult Psychiatry, Nottingham 